\title{
A verdade da repressão
}

\section{Antonio Candido}

Balzac, que percebeu tanta coisa, percebeu também qual era o papel que a polícia estava começando a desempenhar no mundo contemporâneo. Fouché a tinha transformado num instrumento preciso e onipotente, necessário para mạter a ditadura de $\mathrm{Na}$ poleão. Mas criando dentro da ditadura um mundo paralelo, que se torna fator determinante e não apenas elemento determinado.

O romancista tinha mais ou menos dezesseis anos quando Napoleão caiu, e assim pôde ver como a polícia organizada por Fouché adquirira por acréscimo (numa espécie de desenvolvimento natural das funções) o seu grande papel no mundo burguês e constitucional que então se abria: disfarçar o arbítrio da vontade dos dirigentes por meio da simulação de legalidade.

A polícia de um soberano absoluto é ostensiva e brutal, porque o soberano absoluto não se preocupa em justificar demais os seus atos. Mas a de um Estado constitucional tem de ser mais hermética e requintada. Por isso, vai-se misturando organicamente com o resto da sociedade, pondo em prática um modelo que se poderia chamar de "veneziano" - ou seja, o que estabelece uma rede sutil de espionagem e de delação irresponsável (cobertas pelo anonimato) como alicerce do Estado.

Para esse fim, criam-se por toda a parte vínculos íntimos e profundos. A polícia se disfarça e assume uma organização dupla, bifurcando-se numa parte visível (com os seus distintivos e as suas siglas) e numa parte secreta, com o seu exército impressentido de espiões e alcagüetes, que em geral aparecem como exercendo ostensivamente uma outra atividade. Este funcionamento duplo permite satisfazer também a um requisito intransigente da burguesia, dominante desde os tempos de Balzac e dispensado só nos casos de salvação da classe: a tarefa policial deve ser executada implacavelmente, mas sem ferir demais a sensibilidade dos bem-postos na vida. Para isso, é preciso esconder tanto quanto possível os aspectos mais desagradáveis da investigação e da repressão.

Para obter esse resultado, a sociedade suscita milhares de indivíduos de alma convenientemente deformada. Assim como os "comprachicos" d'O homem que ri, de Victor Hugo, estropiavam fisicamente as crianças a fïm de obterem aleijōes para divertimento dos outros, a sociedade puxa para fora daqueles indivíduos a brutalidade, a privação, a frustração, a torpeza, a tara - e os remete à função repressora.

Daí o interesse da literatura pela polícia, desde que Balzac viu a solidariedade orgânica entre ela e a sociedade, o poder dos seus setores ocultos e o aproveitamento do marginal, do degenerado, para o fortalecimento da ordem. Nos seus livros há um momento onde o transgressor não se distingue do repressor, mesmo porque este pode ter sido antes um transgressor, como é o caso de Vautrin, ao mesmo tempo o seu maior criminoso e o seu maior policial.

Dostoiévski percebeu uma coisa mais sutil: a função simbólica do policial como sucedâneo possível da consciência - a sociedade entrando na de cada um através da pressão ou do desvendamento que ele efetua. Em Crime e castigo, o juiz de instrução Porfírio Porfíriovitch vai-se tornando para Raskolnikof uma espécie de desdobramento dele mesmo.

Mas foi Kafka, n'O processo, quem viu o aspecto por assim dizer essencial e ao mesmo tempo profundamente social. Viu a polícia como algo inseparável da justiça, e esta assumindo cada vez mais um aspecto de polícia. Viu de que maneira a função de reprimir (mostrada por Balzac como função normal da sociedade) adquire um sentido
ANTONIO CANDIDO é professor aposentado de Teoria Literária e Literatura Comparada da FFLCH-USP e autor de Formação da literatura brasileira (Editora Itatiaia). Seu livro mais recente é a coletânea de ensaios $A$ educação pela noite (Editora Ática).

Este texto foi extraldo do livro Teresina etc., Rio de Janeiro, Paz e Terra, 1980 pp. 113 a 118. 


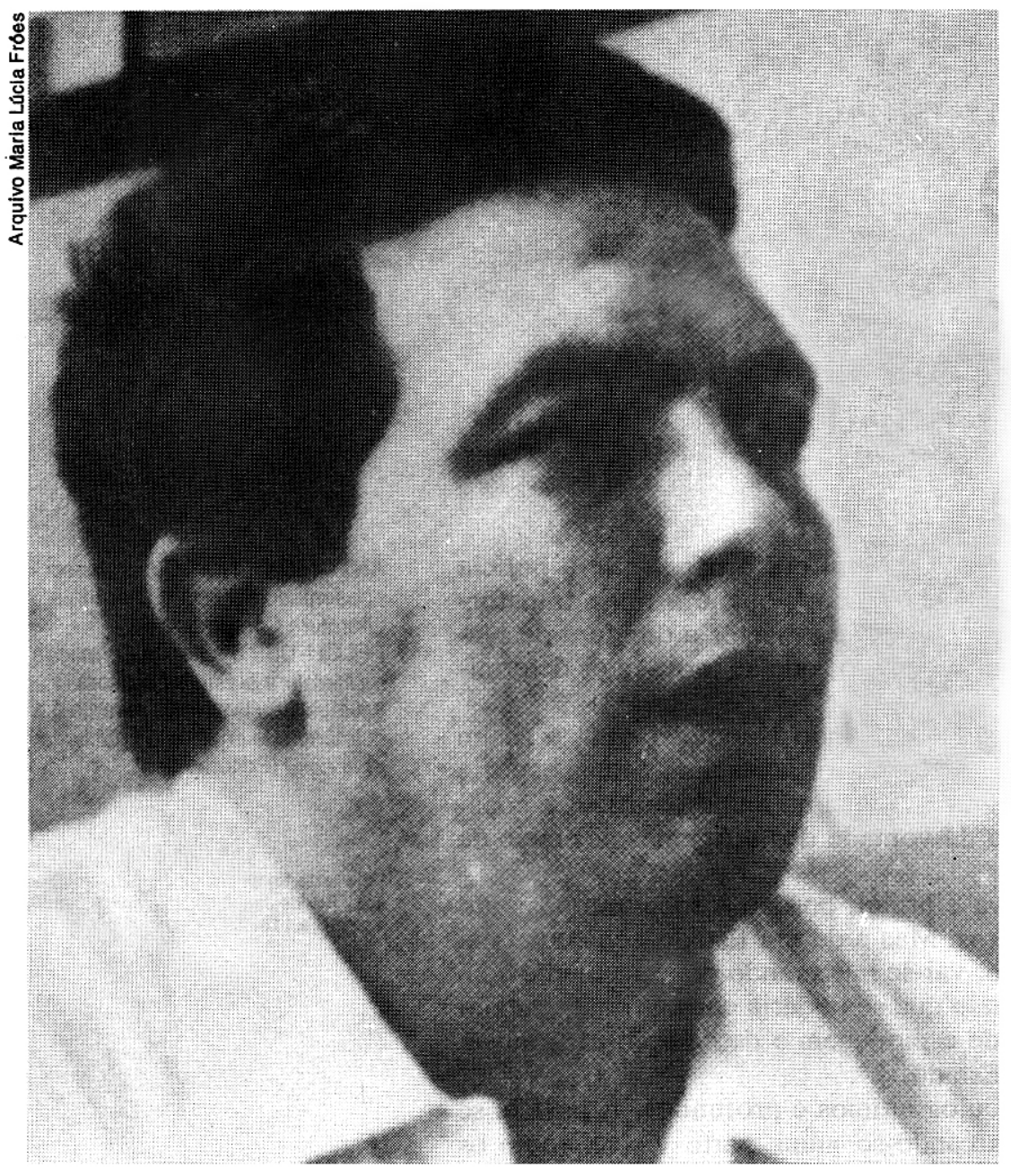

transcendente, ao ponto de acabar se tornando a sua própria finalidade. Quando isso ocorre, ela desvenda aspectos básicos do homem, repressor e reprimido.

Para entrar em funcionamento, a polícia-justiça de Kafka não tem necessidade de motivos, mas apenas de estímulos. E uma vez em funcionamento não pode mais parar, porque a sua finalidade é ela própria. Para isso, não hesita em tirar qualquer homem do seu trilho até liquidá-lo de todo, física ou moralmente. Não hesita em pô-lo (seja por que meio for) à margem da ação, ou da suspeita de ação, ou da vaga possibilidade de ação que o Estado quer reprimir, sem se importar se o indivíduo visado está envolvido nela. Em face da importância ganha pelo processo punitivo (que acaba tendo o alvo espúrio de funcionar, pura e simplesmente, mesmo sem motivo), a materialidade da culpa perde sentido.

A polícia aparece então como um agente que viola a personalidade, roubando ao homem os precários recursos de equilíbrio de que usualmente dispõe: pudor, controle emocional, lealdade, discrição - dissolvidos com perícia ou brutalidade profissionais. Operando como poderosa força redutora, ela traz à superfície tudo o que tínhamos conseguido reprimir, e transforma o pudor em impudor, o controle em desmando, a lealdade em delação, a discrição em bisbilhotice trágica.

Daí uma espécie de monstruosa verdade suscitada pela polícia. Verdade oculta de um ser que ia penosamente se apresentando

Acima, o diretor italiano Elio Petri; na página ao lado, a atriz Florinda Bulcão, em cena de Inquérito a respeito de um cidadáo acima de qualquer suspeita como "outro", que de fato era "outro", na medida em que não era obrigado a recair nas suas profundidades abissais. Aliás, seria mais correto dizer que o "outro" é o suscitado pela polícia. O "outro", com a sua verdade imposta ou desentranhada pelo processo repressor, extraída, contra a vontade, dos porões onde tinha sido mais ou menos trancada.

De fato, a polícia tem necessidade de construir a verdade do "outro" para poder manipular o "eu" do seu paciente. A sua força consiste em opor o "outro" ao "eu", até que este seja absorvido por aquele e, deste modo, esteja pronto para o que se espera dele: colaboração, submissão, omissão, silêncio. A polícia esculpe o "outro" por meio do interrogatório, o vasculhamento do passado, a exposição da fraqueza, a violência física e moral. No fim, se for preciso, poderá inclusive empregar a seu serviço este "outro", que é um novo "eu", manipulado pela dosagem de um ingrediente da mais alta eficácia: o medo - em todos os seus graus e modalidades.

Um exemplo dessa redução degradante é o comportamento do delegado com o encanador, no filme Inquérito sobre um cidadão acima de qualquer suspeita, de Elio Petri.

O delegado, que é também o criminoso, resolve brincar com o destino e como que provar o mecanismo autodeterminante da polícia, a sua finalidade em si mesma. Para isso, dirige-se a um transeunte qualquer, escolhido ao acaso, e confessa que é o matador procurado, dando como prova a gravata azul celeste que usa e fora vista nele. Convence então o pobre transeunte a ir à polícia e relatar o fato, dando-lhe para levar como indício (e evidentemente como baralhamento do indício) diversas gravatas iguais, que mostrariam como era a do assassino. 


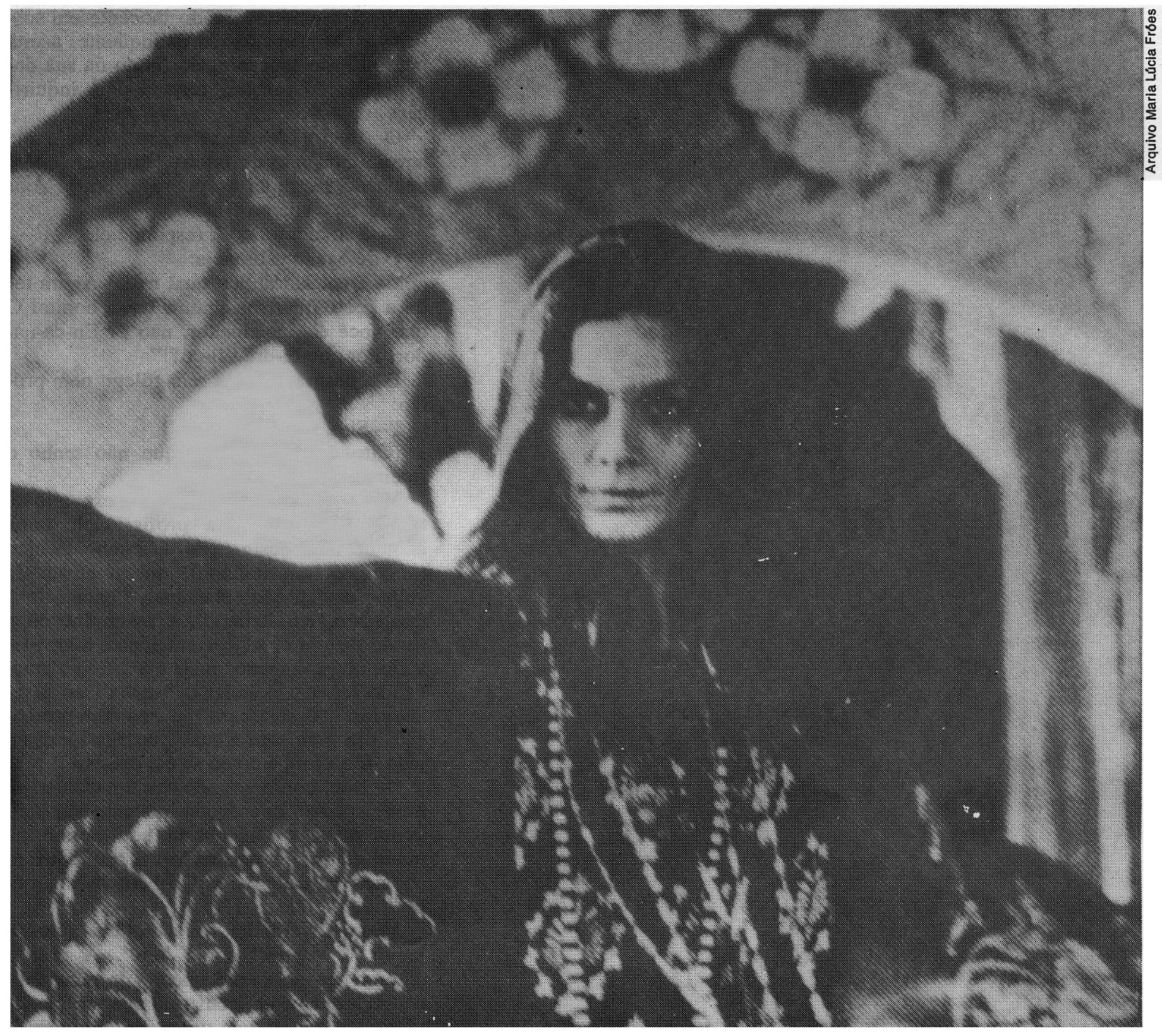

Chegando à polícia, o transeunte, que é encanador, dá de cara com o assassino que se confessara na rua, e que ia delatar; mas que agora está no seu papel de delegado. Este o interroga com brutalidade e o pressiona física e moralmente para dizer quem era o assassino que se desvendara a ele na rua. Mas o pobre diabo, completamente desorganizado pela contradição inexplicável, não tem coragem para tanto. Com isso, vai ficando suspeito, vai-se caracterizando legalmente como possível criminoso, até desaparecer dos nossos olhos, trôpego, arrasado, por uns corredores sujos que levam aonde bem suspeitamos.

A força que o paralisa, e que nos paralisaria eventualmente, vem de uma abigüidade, misteriosa na aparência, mas eficaz, cuja natureza foi sugerida acima: o repressor e o transgressor são o mesmo, não apenas fisicamente e do ponto de vista dos papéis sociais, mas ontologicamente (o "outro" é o "eu").

Tudo nesse episódio é modelar: a gratuidade com que se escolhe o culpado; a imposição de um comportamento não intencional (ir à polícia com as gravatas azuis no braço, delatar um criminoso sem nome, que não interessa); o baralhamento da verdade, quando ele constata que o homem que se denunciara como assassino é também o dele- 


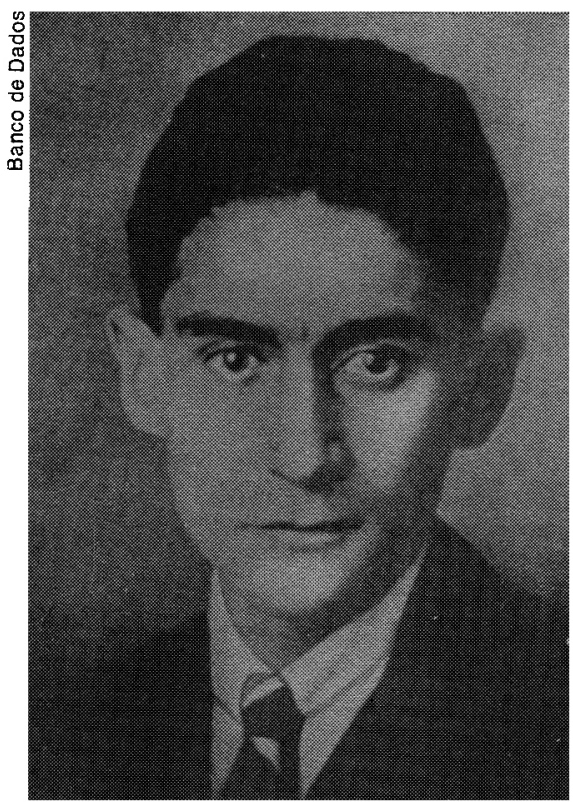

Acima, Franz Kafka; ao lado, Fiodor Dostoiévski gado; a transformação do inocente em suspeito e do suspeito em delinqüente, aceita pelo próprio inocente, do fundo da sua desorganização mental, forjada pela inquirição.

O fulcro desse processo talvez seja aquele momento do interrogatório em que o delegado pergunta ao pobre diabo, já zonzo, qual é a sua profissão.

"-Sou hidráulico", responde ele.

O delegado esbraveja:

“- Qual hidráulico qual nada! Agora toda a gente quer ser alguma coisa bonita! $O$ que você é é encanador, não é? En-ca-nador! Por que hi-dráu-li-co?!"

E o desgraçado, já sem fôlego nem prumo:

"-Sim, sou encanador."

(Cito de memória porque não tenho o roteiro.)

Vê-se que o pobre homem, a exemplo de toda a sua categoria profissional, tinha adotado uma designação de cunho técnico (idraulico, em italiano), que o afasta da velha designação artesanal "encanador" (stagnaro, em italiano), e assim lhe dá a ilusão de um nível aparentemente mais elevado, ou pelo menos mais científico e atualizado. Mas o policial o "reduz" ao nível anterior, "desmascara" a sua autopromoção, tira para fora a sua "verdade" indesejada. E no fim, é como se ele dissesse:

“- Sim, confesso, não sou um técnico de nome sonoro, que evoca inocentemente alguma coisa de engenharia; sou mesmo um pobre diabo, um encanador. Estou reduzido ao meu verdadeiro 'eu', libertado do 'outro"'.

Mas na verdade, foi a polícia que lhe impôs o "outro" como "eu". A polícia efetuou um desmantelamento da personalidade, arduamente construída, e trouxe de volta o que o homem tinha superado. Sinistra mentalidade redutora, que nos obriga a ser, ou voltar a ser, o que não queremos ser; e que mostra como Alfred de Vigny tinha razão, quando anotou no seu diário: "Não tenha medo da pobreza, nem do exílio, nem da prisão, nem da morte. Mas tenha medo do medo". 